\title{
HOT-AIR SHOWER BATHS FOR VETERINARY PURPOSES
}

\author{
BY DR. ALFRED GRADENWITZ
}

Electric hot-air fans have been employed for some time in medical practice, and have undergone during the last few years most interesting alterations as regards form and use. In their original form they were used for drying hair by means of an air current produced by an electric fan, and heated by an electrical resistance.

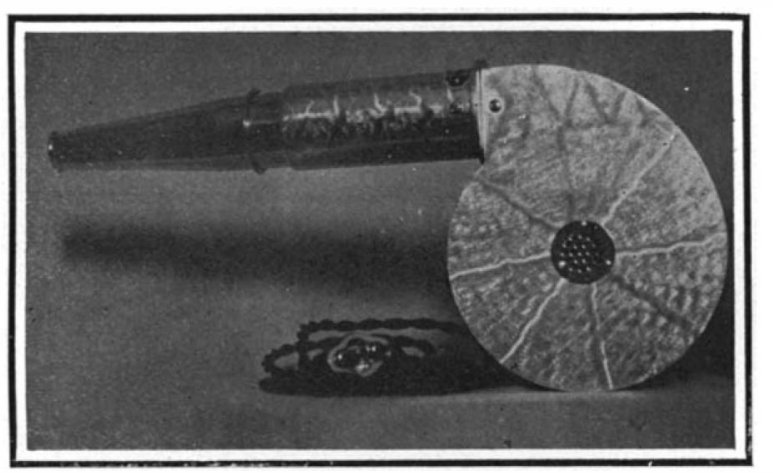

THE HOT-AIR VENTILATOR. A SERIES-WOUND ELECTROMOTOR IS HIDDEN IN THE HANDLE.

This current of heated air was soon found to possess striking curative effects. In connection with maladies such as gout, rheumatism, neuralgia, etc., a daily application lasting ten to fifteen minutes would alleviate and in the case of prolonged treatment, even cure these ailments. It is true that the limbs affected, be- ing especially susceptible to cold after the treatment, had to be carefully protected by warm clothing.

Some time after the new treatment had been introauced in medicine, hot-air currents were found to exert striking curative effects on morbid tissues, and in furunculosis, abscesses, etc., on account of the hyperæmia (abundance of blood) produced by them. Thus, hot-air shower baths have been adopted in an extremely short time, not only in hospitals and sanitoria, but in the consultation rooms of specialists, as.well as tho of the ordinary practitioner. Their ase case of handing, the readiness of the hot-air fans for use in working at a moment's notice, after being con-
nected with an ordinary contact box, and the control nected with an ordinary contact box, and the control
of the heat effects at will by a special switch, have of the heat effects at will by a special switch, have greatly facilitated the adoption of the shower baths. In fact, hot-air ventilators are able to generate in half a minute a strong air current up to 212 degrees $F$. a result impossible with any other apparatus.

The electrometrical instrument factory of Dr. Richard Heilbrun in Berlin has recently extended the use of hot-air shower baths to veterinary practice. The ventilator used in this connection comprises a serieswound electromotor hidden in the handle of the apparatus. The electrical radiator heating the drawn-in air current to a temperature up to 212 degrees is carried by a connection tube 40 millimeters in diameter. The weight of the apparatus is about 2 pounds; the current consumption of the motor under a tension of 220 volts is 0.2 ampere, and that of the radiator amperes. A nickel funnel, 100 millimeters in length and 20 millimeters in diameter, fitted over the mouthpiece allows a hot-air current of increased intensity to be generated, which is particularly valuable in connection with a localized treatment.

As dogs and horses are especially susceptible to

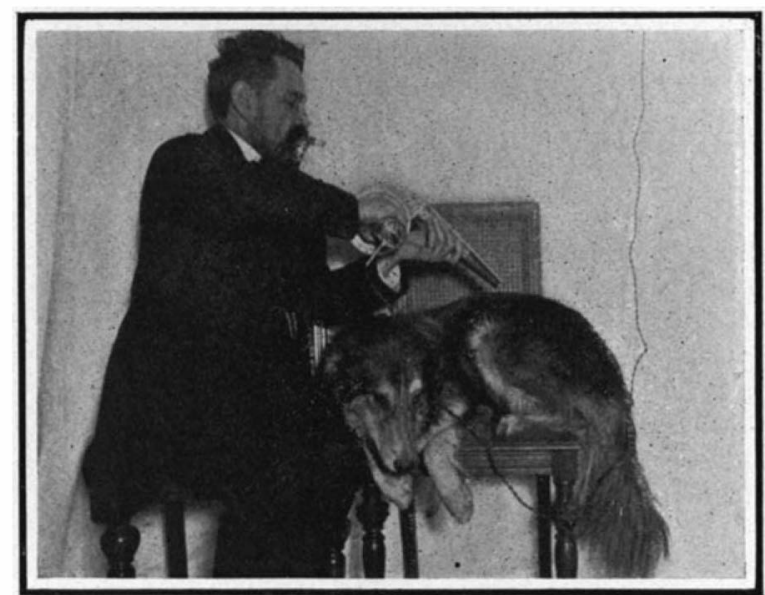

THE HOT-AIR SHOWER BATH AS OPERATED IN LOCALIZED TREATMENT.

catching cold, the hot-air shower bath affords an effective means of alleviating and curing their ailments, even the most nervous dogs becoming accustomed to the unusual treatment after its first application.

\section{THE MICROSCOPE AS FOOD DETECTIVE}

\section{B Y P. HARVEY MID DLETON}

Probably no other form of wrongdoing so vitally affects us as tampering with our foods and medicines. Of course, the law allows the presence of a certain percentage of preservatives in foods, but it is the excess of this allowance that causes a continuous war to be waged between the traders and the representatives of the law. And so profitable a proceeding is the importation of inferior material into the food of the American public, that many large firms employ skilled chemists at a high salary in order that their expert knowledge may assist them to drive a coach and four through that most far-reaching and radical law of modern times, the Food and Drugs Act of June 30th, 1906 , and fatten on the proceeds.

In what a remarkable manner our food is tampered with may be gleaned from the fact that a large and highly-trained staff of inspectors and their assistants are engaged under the Food and Drugs Act to detect offenses of this kind; and great are the difficulties with which they have to contend. For instance, it is chemical task to prove that poisonous copper salts ar applied to bottled vegetables to give them color, and microscopic achievement to show that a concoction labeled and sealed as arrowroot is nothing of the kind, but chiefly potato starch. It is difficult to prove who puts brick dust peroxide of iron or arrowroot in a puts brick dust, peroxide of iron, or arrowrot in a syrups, and drugs to make them more attractive to the eye. One such frequently-used violet coloring matter boasts a name of fifty-five letters which reads diethyldibenzyldiethytriamidotriphenylcarbinoldisulfone.

The alleged olive oil used in salads is often cotton-

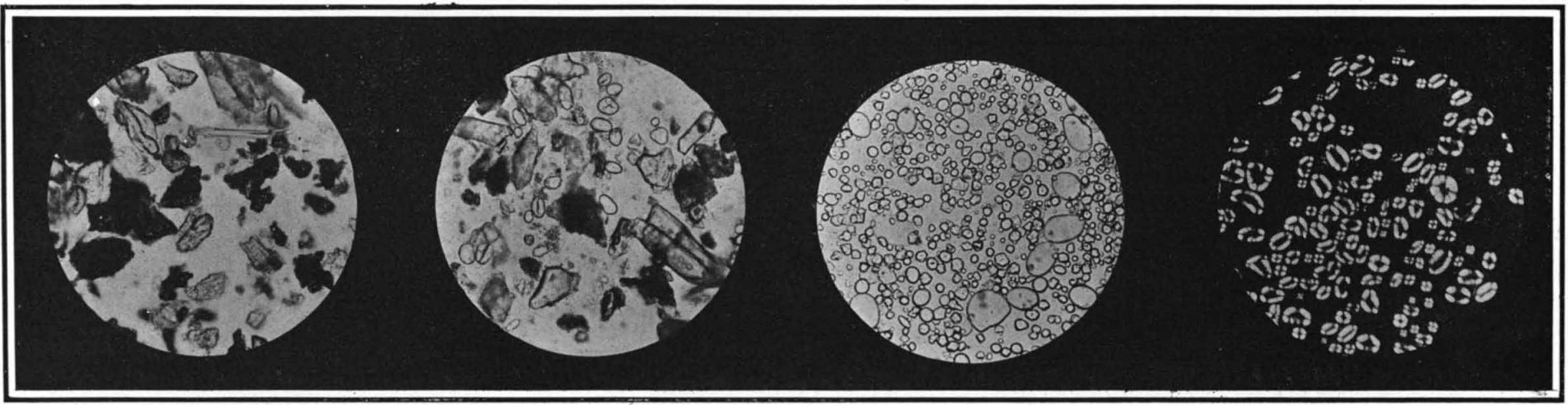

Black pepper adulterated with ground olive pits.

The pepper starch has been colored blac iodin, causing the olive cell
to appear in contrast.

The angular bodies are pepper starch,
and the rounded bodies are bean starch which is used as an The round grains are potato starch, and the angular grains ar
corn starch, used as Bean starch photographed with polarized light showi
characteristic optical

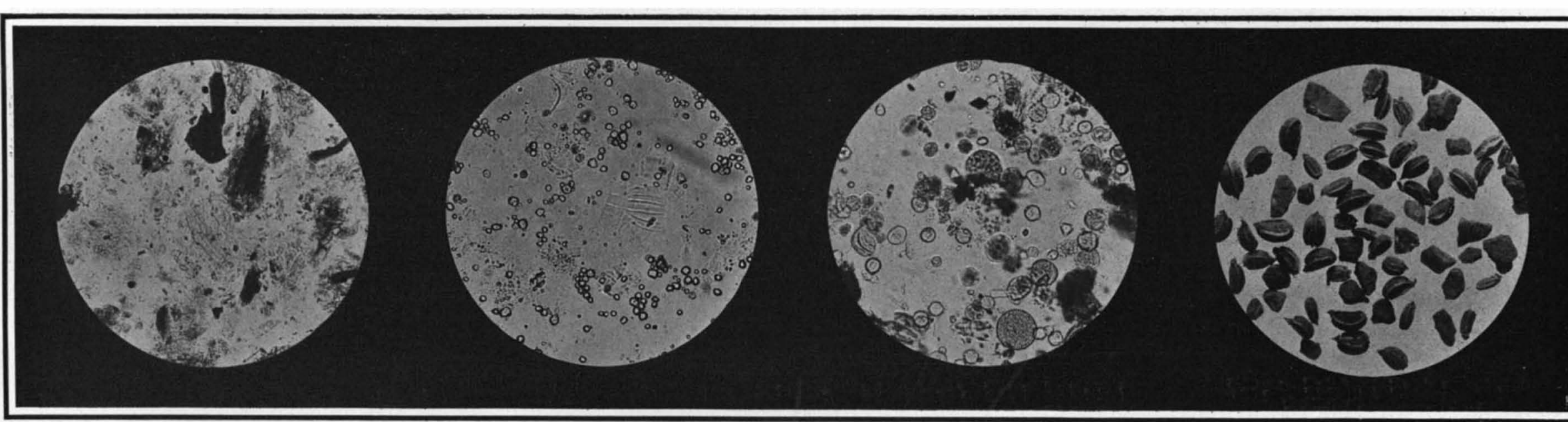

Chicory, showing some of the characteristic sa vessels by which it is detected whe

Cream thickener composed oi corn starch (angula bodies) and gum tragacas
portions).
Pollen from honey. The varions forms by the bees.
Ceiery seed adulterated with ground rock, the latter indentified by its

THE MICROSCOPE AS FOOD DETECTIVE, 
seed oil; and such substances as burnt sugar, Cayenne pepper, acetic ether, tannin, crude cream of tartar, and French plum-juice are frequently imported into brandy and whisky.

The term "adulteration" when applied to food or drugs is broad in its scope, but has been given a welldefined legal meaning. In general it may be said that adulteration consists in injuriously subtracting from a substance any part of its natural or inherent qualities or adding to it any ingredient which would render the or adding to it any ingredient which would render the
article of a different nature than that of its expressed article of a differ

Almost coexistent with the growth of this wonderful country, and seemingly as a part of the fierce business competition which has insidiously developed, this evil of food and drug adulteration has arisen. The conditions of substitution and adulteration of foods and drugs were little short of deplorable less than a decade ago. For seventeen long years the bill which has now become the Pure Food Law lay at the door of has now become the Pure Food Law lay at the door of
Congress, and during all that time it was bitterly opposed by the manufacturers who had so long enjoyed posed by the manufacturers who had so long enjoyed
unmolested their privilege of supplying the dinner tables of the nation with impure foods misleadingly labeled.

While this act has done much good, there is still a very considerable amount of adulteration practised. Pepper adulteration is still remarkably common, and "Pure White Clover Honey" is concocted by the imitators of the busy bee from glucose. Other enterpristators of the busy bee from glucose. Other enterpris-
ing manufacturers will cause two grains of Cayenne ing manufacturers will cause two grains of Cayenne
pepper to grow where only one grew before, by making one of the grains grow out of sawdust. Ground peas and beans may be found in black pepper, and celery seed may be adulterated with forty per cent of powdered rock.

In order to run down one class of food faking, the pure-food experts at Washington have introduced the microscope into their work. It can be readily understood how gross adulteration may be detected by a simple microscope, as for instance when foreign seeds, ple microscope, as for instance when foreign seeds,
gravel, or powdered rock have been mixed with whole small spices. The adulterant may be of such a character as to escape the notice of the ordinary buyer, though with even a small lens or reading glass the foreign substance may be seen to be very different from the true spice.

The usefulness of the simple magnifier in examining food and drug materials, however, is of little value for the examination of products which are made up of small particles, such as fiour, ground spices, and powdered drugs. In such cases recourse must be had to the compound microscope, with a magnifying power ranging from fifty to four hundred diameters.

The world's supply of starch comes for the most part from a limited number of plants; twelve or fifteen include nearly all that are of much commercial importance. To the naked eye these starches all appear as a fine white powder, but under a microscope grains or granules are seen which vary more or less in shape, size, rings, nucleus, and action toward polarized light. Some of the grains are almost spherical, others are angular or ovoid, and still others are very irregular in outline. In diameter they vary from one-tenth to onethousandth of a millimeter. In no variety are all the starch grains of one size, but usually there are fairly well-defined limits. The way in which they sometimes vary will be seen by reference to the photographs reproduced in this article. Most of the grains show, produced in this article. Most of the grains show,
more or less clearly, fine lines of rings upon the surmore or less clearly, fine lines of rings upon the sur-
face. In some varieties these are arranged concentrically, while in others they are eccentric.

"A hilum (nucleus) whose form and position varies widely in certain species commonly occurs in starches," says B. J. Howard, who has charge of this microscopical work in the Bureau of Chemistry at Washington. "In some it is at the center, as in corn and wheat starches, in others near one end, as in potato and arrowroot. When viewed in polarized light, starches show more or less strongly a cross with the bars passing through the hilum. Wheat starch has a central cross, while in maranta it is eccentric and well defined. Bean starch, which illustrates the leguminous type, has a spindle-shaped cross. In the oat a number of starch granules are joined together, forming a mass. When these masses of starch are examined under polarized light, individual grains in the mass have their own individual effect, and interfere so with each other that there results Iittle more than a hazy glow of light."

By becoming familiar with these characteristics, it is possible to identify with considerable accuracy rearly all of the commercial starches. Potato starch adulterated with corn starch, wheat with corn flour, and buckwheat with wheat are examples of those most easily detected. One of our photographs shows a picture of potato starch adulterated with a considerable amount of corn stareh. The grains of the latter are easily distinguished by their angular form.

Another interesting application of the microscopic method of food analysis is found in the examination of spices. Many of these naturally vary so widely as
to ash, fiber, etc., and in taste that it is impossible to identify certain kinds of adulteration by chemical and physical means alone. A study of the structure of pure samples will usually fit the analyst to detect adulteration in the ground spices as well as to identify the adulterant used. In order to work most intelligently, however, it is imperative that the analyst should have a good foundation in histological botany, since in this class of products the plant cell in its various modifications becomes the means of identification. In an examination of this sort nearly all kinds of plant tissue are to be considered, because some spices are derived from roots, as ginger, some from barks, as cassia and cinnamon, some from flowers, as cloves, some from seeds, as. mustard, some from fruits, as red pepper, black pepper, etc., and some, such as sage and thyme, from leaves.

"Unfortunately," says Mr. Howard, "most of the substitutions used for adulteration have a structure very different from the genuine spices. For example, although pepper may be adulterated with ground peas, or beans, it may not always be detected by chemical means, especially when olive pits or pepper shells have been added to counteract excessive starch present in beans. A microscopical examination will reveal such adulteration at once by showing the presence of the large starch grains characteristic of certain legumes. In pepper the starch is
masses made up of small grains."

It sometimes occurs that a manufacturer has added so large an amount of corn meal or foreign ground shells and fruit stones to a pepper as to make the adulteration apparent to the taste by the lack of pungency, which is often corrected by adding a small amount of Cayenne pepper. A sophistication of this kind can be readily detected by the microscopic method of analysis, because the tissues added are so distinctly different from normal pepper tissue. In one of our photographs is shown the microscopic appearance of a sample of pepper which was grossly adulterated with ground olive stones. The starchy material has been stained black in the picture, while the partly clear porstained black in the picture, while the partly clear por-
tions, more or less oblong in form, are the stone cells tions, more or less
of the olive pits.

of the olive pits.

The capsicum fruits are readily identified by means of certain cells found on the inner portion of the pericarp (pod) and others on the seed coats. These cells have characteristic sinuous outlines which make them easy to detect even when present in very small numbers.

In coffee and chocolate preparations roasted chicory, cereals, and peas in the case of the former, and starchy materials and cocca shells in the case of the latter, are sometimes used for adulteration. Coffee, being the seed of a plant, has a structure which is very different from chicory, which is a root. The cell walls of coffee have a characteristic beaded appearance which is present in but few other seeds. Even after roasting and grinding these beads can be easily distinguished, while chicory contains sap vessels by which it can be while chicor

Chocolate and cocoa are made from the seeds of the cocoa plant, to which foreign starches are sometimes added. Cocoa beans contain naturally a considerable amount of starch. The grains are small in size and are easily distinguished from the starchy adulterants, such as corn and wheat flours, or potato, corn, and arrowroot starches. An artificial chocolate coating has been examined which was composed of cocoa shells, corn starch, beef tallow, and some mineral matter probably used as a coloring substance.

In the production of artificial jellies, jams, and some kinds of confections various thickeners are used, among which might be mentioned gelatin, starch, agaragar, gum tragacanth, and gum arabic. Some of these are difficult of identification, while others can readily be detected. Agar-agar is a product made from certain seaweeds, and usually contains the siliceous shells of diatoms. These shells are characteristic and quite easily detected in the sediment from the bottom of a dish after the material has been digested with dilute nitric acid. One of our photographs shows such a diatomaceous shell obtained from a sample of artificial "lemon slices" in which was found that the jellying material was agar-agar.

Starch can easily be detected by microchemical and microscopicăl tests. Gum tragacanth and some other gums of this class contain a certain amount of small starch grains. When allowed to swell in water, a delicate laminated structure is developed by which these gums are disclosed even in such products as ice cream and marmalades.

A sample of thickener for cream composed of corn starch and powdered gum tragacanth is shown herein, and illustrates this feature quite satisfactorily. In this case the corn starch is shown plainly as the angular the field are swollen fragments of the gum. The microscope is also of service in the examination of certain edible fats. Thus, if pure lard is dissolved in ether and the latter is allowed to evaporate slowly under proper conditions, crystals of the lard will be formed. These, if normal, will appear under the microscope as
narrow plates with chisel-shaped ends. Beef fat

reated in a similar manner will normally crystallize out in sheaf-like tufts of crystals, the ends of which are nearly or quite needle-like.

Another application of microscopic analysis is in the dentification of the flowers from which honey is made. This is of practical value in the analysis of honeys purporting to be from certain flowers. Although bees will almost invariably gather honey from several kinds of flowers, sometimes one or another of these predominate to such an extent as to impart a distinctive colo and taste, enough to allow the honey to be called by that name. By microscopic examination it is readily ascertained whether a so-called apple-blossom honey or an orange-blossom honey is really largely derived from the source claimed. A photograph showing several kinds of pollen found in an ordinary sample of honey is reproduced.

\section{Goxxespondence.}

THE INVENTION OF THE PLAYER-PIANO

To the Editor of the Scientific AMERICAN:

1 must file a demurrer to an impression created by the illustrated article which appeared in your issue of the 9th inst., under the heading "Ringing Chimes McTammany as one of the inventors of the playerpiano, I think an erroneous impression is thus conveyed regarding McTammany's true relation to the development of the player.

As a matter of fact, he is known and conceded to be Alather of the player by everyone in the piano trade iliar with the player history, and his claims to Wentorship stand unchallenged up to this momen do not refer to McCormick as one of the inventor f the reaper or to Howe as one of the inventors of the sewing machine nor to Cristofori as one of the inventors of the piano, although other men besides those mentioned contributed greatly to the development and improvement of the aforesaid inventions.

The history of every great invention has demonstrated that some one man has stood out pre-eminently from all his fellows in the course of its development, and the player has been no exception; and the one man who above all others stands forth pre-eminent in the player field is John McTammany, while around and about him, like so many satellites, have stood other men who have contributed of their genius to develop and improve the invention. In the case of the reape it was McCormick who overshadowed all his contemporaries; on the other hand, Howe was the presiding genius who led the sewing-machine pioneers, while Cristofori was the pre-eminent genius who first conceived and developed the piano.

It is true that others have improved upon the handwork of McCormick and Howe as well as upon that of Cristofori, but nobody has been able to eliminate the elements which they introduced into their respective inventions; and so long as those essential element remain in their respective devices, just so long those inventions shall be attributed to the men we have mentioned. But the piano invented by Cristofori was mute and silent piano, and such it remained from the time it was invented, in 1709 , until 1876 , when John McTammany breathed within its wooden wail the breath of life, and henceforth it became a living. breathing, yea, almost a human thing, until to-day it stands forth the unsurpassed and unchallenged kin of musical instruments. The following definition of the player has "Player, a musical instrument consisting of a casing, two
actions, and a series of sounding devices within the casing,
one of said actions adapted to be operated manually, the other designed to be operated to be operated manually, the forated sheet on rolls; a wind, spring, or other motor for reeding the sheet and winding the rolls; a bellows and mechan ism put in motion by it for actuating the sounding devices
of the automatic action, foot pedals or power for driving the of the automatic action, foot pedals or power for driving the
motor, and means for controlling the tempo and varying the

Now the first man to embody the foregoing elements in a musical instrument was John McTammany, an it follows that if McCormick is the inventor of the reaper, Howe of the sewing machine, and Cristofori of the piano, by reason of the fact that they were the first to embody in their respective devices the essential elements which distinguished those inventions today, and the elimination of which would make them worthless, then by the same token John McTammany. must be regarded as the father of the piano-player mechanism, for no practicable or salable player has yet been made that did not contain the elements first 